\title{
REVOLUTION IN COMMUNICATION TECHNOLOGIES: Impact on Distance Education
}

\author{
M. RAJESH \\ Regional Director, \\ IGNOU Regional Centre, Cochin, INDIA
}

\begin{abstract}
Information and Communication Technologies have transformed the way the world lives and thinks. Education, especially, Distance Education is no different. While the technologies per se are an important factor, the social milieus in which these technologies are implemented are equally important. Technological convergence in the Indian context surely has to account for "Old Generation Technologies" on their platform as much as new technologies. The vibrant interface between social and technological issues in the Educational field is an important area of discourse. The current paper discusses these and many more issues in ample detail.
\end{abstract}

Keywords: Communication Technology, Technology and Distance Education in India, Convergence of technologies.

"The virtue of a computer in the classroom is that it requires a user, not a watcher."

-Diane Ravitch

\section{INTRODUCTION}

Diane Ravitch's interesting quote perhaps sums up the essence of education in the $21^{\text {st }}$ century. Technologies have to come to rule and even dictate the terms on which pedagogic discourse is undertaken the world over. Despite the seemingly over-whelming nature of technological intrusion into academic discourse, the many questions that remain to be answered are whether there has been a revolution or has it been an evolution? If it is indeed a revolution as many would like us to believe, how has it impacted the ways in which we teach, study or transact academically? Further, has it been a systemic revolution? Do technologies impede the development of traditional competencies in teaching and learning? Are all technologies value neutral? Finally, perhaps most important one is - can technologies replace the teacher?

Such questions are often asked at the cross roads of major technological changes. The present era seems to project one such scenario. New educational technologies are constantly being unveiled and older ones are constantly modified or updated. 


\section{PAST STUDIES}

A number of studies conducted in the past by scholars namely, Dziuban, (2002); Navarro and Shoemaker, (2000), Hilgenberg and Tolone, (2000); Keegan, (2000), Smith, Ferguson, and Caris (2003) and Mason (2000) reveal the following facets (Gaudelli, 2006):

$>$ There exists a higher level of student satisfaction in web-based distance learning than through face-to face learning

$>$ Matched or exceed achievement of distance learning students when compared to face-to-face situations

$>$ Increased engagement in a-synchronous discussions, which would motivate learners to continue in the programme

$>$ Even in subjects like Mathematics, the effectiveness of ICT based learning and the levels of involvements of learners were found to be far higher than that of Face to Face Learning

However, ICT based learning pedagogy is not without its vibrant critics. Postman states that technology integrated learning is a form of edutainment which threatens to unravel our social fabric. Clark states that the ICT based modality of instruction does not translate into a significant difference in student achievement. Russell (2002) based on his study of an extensive database of $\mathbf{3 5 5}$ citations to educational articles over the past century that document no significant difference in student achievement when distance learning is compared to traditional modes (Gaudelli, 2006).

It can clearly be seen that there are few major studies on how technologies have converged to create a more democratic learning space. The current study is an effort in the direction of addressing this vital issue.

\section{THEORETICAL UNDERPINNINGS ON USE OF NEW TECHNOLOGIES}

Firstly, we shall see what "Emerging Technologies" or new technologies are. Miller, Green and Putland define Emerging Technologies as:

"A technology is still emerging if it is not yet a must have. For example, a few years ago, E-Mail was an optional technology. Infact, it was limited in its

effectiveness as a communications tool when only some people in an organization have regular access to it. Today, it is a must have, must use

technology for people in most organizations. In this sense, a technology can be a standard expectation in the commercial or business world, while still being considered as "emerging" in the educational sector" (Veletsianos, 2010).

Some of the major theoretical strands that go behind the adoption of new technologies are as given below:

\section{The Constructivist Approach}

Constructivist theories derive their popularity from the writings of Jean Piaget, Dewey and Mead. Though there are a large number of theories that signify constructivism, they all share a common strand, which is that individuals of all kinds construct knowledge based on their understanding of their backgrounds and proclivities. Constructivism also claims that learning takes place when the tasks those are being done hold meaning for the learners and are 
contextual in nature (Veletsianos, 2010). These techniques require problem focus and elaborate techniques of enquiry (Veletsianos, 2010).

\section{Complexity Theory}

The Complexity theory involves the study of living systems and focuses on how a living organism adapts to changing living environments. In the effort to survive in the changing external setting, the organism, modifies the external setting and in the process creates complex yet stable systems (Veletsianos, 2010). The said theory attempts to predict phase transitions that provide for growth, change or learning. This theory imagines learning contexts (class rooms, online learning etc) as entities themselves.

\section{Net-Aware Theories}

The Net-Aware theories look at three distinct affordances as far as teaching- learning processes is concerned (Veletsianos, 2010):

$>$ The capacity for powerful yet Low Cost Communication, which encourages epistemic engagement in teaching- learning processes. Net-based technologies provides avenues for collaborative, informal and life-long learning

$>$ Net based technologies create a mechanism whereby we move from a position of information and content scarcity to one of sheer abundance.

$>$ Internet provides active agents that compile and present relevant information according to one's needs. The search -Engine is one such manifestation.

\section{Heutagogy}

Hase and Kenyon coined the term, "Heutagogy" to signify self directed learning that dispenses with the need for the teacher that is characteristic of pedagogy and andragogy (Veletsianos, 2010). The authors predict that the future of learning will be a movement away from competency building to capacity building. It is also a movement away from prescriptive contents to exploration of issues that affect the students' life (Veletsianos, 2010).

\section{Activity Theory}

The Activity Theory states clearly that all human activity is oriented towards goal attainment and that this process is mediated by tools- either mediated or physical. (Kirkwood, 2005). Training of learners through activities is a sure way of inculcating the requisite and desired skills. The selected technologies should be such that they aid and promote the desired learning outcomes.

The choice of technology is integrally linked to the level of understanding that is sought to be achieved. Learning typically goes through four distinct stages. The first level is characterized by information assimilation and reproduction.

Traditionally, such learning has been associated with learning by rot and therefore reinforcement of memory is an important aspect in this scheme. To cater to such requirements, technologies that promote maximum information flow, seem most suitable. The notable examples of such technologies are Peer to Peer (P2P) technologies, virtual class rooms, podcasts and so on.

The second stage of learning is synonymous with practical learning in which the theoretical learning is converted into functional understanding by hands-on training. The most relevant technologies in this scenario relate to web-based as well as practical computer models. 
The third stage is one of reflective learning or in other words, applying the knowledge acquired in different practical scenarios. In this stage technologies like web based workbooks would be real assets.

The fourth stage is that of Analysis by the learners. At this stage, skills of a higher order need to be inculcated into the learners.

As a natural corollary of what is stated above, it can be easily perceived that the most intensive and attention catching technologies need to be brought into the pedagogic framework in the initial stages of curricular transaction and more functional technologies can be utilized.

\section{NEW TECHNOLOGIES IN FOCUS}

In this section we shall focus on some of the new technologies or emerging technologies relevant to the field of Education and Distance Education in particular. The underlying philosophy behind Technology Enabled Pedagogic method is that knowledge is created through engagement, dialogue and interactivity. In this scheme, knowledge is subjective and methods of learning are focused on interaction, participation and dialogue. Students are also active and initiative taking (Anderson, 2010).

\section{Personal Learning Networks}

Personal Learning Networks (PLNs) provide learning platforms that suit particular learning needs of the learner community. The most well known among these PLNs are WebCT/ Blackboard, Moodle, Ning and wiki. Let us analyze the comparative merits and demerits of these mechanisms.

\section{WebCT/Blackboard}

WebCT is an online proprietary Virtual Learning Environment that is licensed to colleges and other institutions mainly for the purpose of E-Learning.

It was initially developed by Murray Goldberg. WebCT is an important technological innovation in the sense that, it was the world's first and most widely used E-Learning Plat form. At the height of its popularity, it catered to the needs of more than 10million students in more than $\mathbf{8 0}$ countries. It is seen that WebCT works well with students who have prior acquaintance with online learning.

The major drawback of the system is that it is a proprietary system that cannot be modified without the vendor's permission. Further, the LMS favours Directed Learning compared to Constructive Learning and is also costly in terms of license fees (Veletsianos, 2010). The over reliance of the LMS on Java, its use of multiple browsers and need for inactivating pop-up blockers are regarded as some of its other major drawbacks.

\section{Moodle}

Moodle is a Course Management System (CMS), also known as a Learning Management System (LMS) or a Virtual Learning Environment (VLE). It is a free web application that educators can use to create effective online learning sites (MoodleTrust). The major advantage of Moodle is that it can scale up its size to meet the personalized requirements of thousands of learners across the globe. Further, the Moodle comes in as a handy tool for "blended Learning", that is to augment class-room teaching. Further, collaborative communities can also be easily built around the Moodle (MoodleTrust). From an educationist's point of view the greatest benefit of 
Moodle is that it encourages a "constructivist", "instructive" and "social constructionist" approach with its wide range of tools (Veletsianos, 2010). Above all Moodle affords modification and has a strong community support (Veletsianos, 2010).

\section{Ning}

Ning is an online platform for people and organizations to create custom social networks. It was launched in 2005. Ning was co-founded by Marc Andreessen and Gina Bianchini. It enables users to launch their own community networks on any specific desired issue area. It can easily integrate with a Face book or Twitter account. Ning, at its inception was "free software" with provisions for altering its code according to user needs. However, the major drawback of Ning is its lack of wiki type features and awkwardness in using core content materials (Veletsianos, 2010). Overtime, Ning has been affected by problems related to hosting third party content. However, the fact remains that Ning remains a very popular social networking site, though not exclusively for educational purposes.

\section{Wiki}

One of the advantages of most Wikis is that they are free and at the same time provide substantial technical support. A case in view is www.wikispaces.com . Collaborative wiki models are also popular. Such collaborative models enable student edit options, digital pedagogies, mobile learning, podcasting, screen casting and so on. Wikis normally enable users to utilize multiple media and are therefore attractive to the learners.

\section{A-View}

India's own A-View is another techno-tool that can be converted into an effective PLN. A-VIEW, developed by Amrita University, is part of Talk to a Teacher program led by IIT Bombay and funded by NME-ICT, MHRD. Approximately 20000 colleges in Indian shall soon be linked to the A-View Distance Learning platform (Amrita-Virtual-Interactive-E-Learning-world, 2013). The technology provides a number of innovative facilities to the teachers as well as the learners. These include, Interactive chat board, Digital White Board, 2D, 3D and video sharing, Desktop and Application Sharing, Library and Quizzes and Polls. The most attractive aspect of this facility is that it has almost all applications those are present in commercial applications while being a free service. The negative aspect of this technology is that it still needs to be perfected. The platform invariably fails to function in low band width conditions. Such conditions obtain at most places in India.

\section{Wiz-IQ}

Wiz IQ is a major online virtual learning platform that has caught the imagination of many educators.

The advantage of the platform is that it can be used without any installation and works on any operating system. The platform affords keyboard shortcuts in the Virtual Classroom, and switch between multiple tabs of the online whiteboard $(I Q, 2013)$. Further, the educator may invite any number of attendees, from just one student for one-on-one tutoring, to 1000 people, who want to attend the online session (IQ, 2013). Another impressive feature of this platform is that "white board" linked tools such as mathematical tools, language tools, group objects, drawing tools etc are built into it. Online videos and customized audio can be integrated into the system. Like A-View, this mechanism also supports Quizzes and polls. The only drawback of the system is that it is a paid service beyond the initial limit. 
There is however a number of challenges as far as implementation of Personalized Learning Platforms are concerned. The first and foremost among these involves the integration of the existing Learning Management Systems (LMS) of the host institutions with that of PLEs.

Many of the institutions have their own LMS in place based on traditional technologies (Veletsianos, 2010). These may not integrate fully and easily into the PLEs. The second aspect involves the technical expertise required to manage and run a PLE. Since most PLEs run on a number of varied platforms and the applications may also not be of a uniform type, the technical expertise required to run the platform could be immense.

\section{Web 2.0}

Web2.0 of second generation applications on the World Wide Web is a set of innovative technologies that are smarter and leaner than those found on Web 1.0. The most important applications in Web2.0 are those associated with sharing of content among users. Collectively, these applications are known as Social Software and include but are not limited to Web logs, Really Simple Syndication (RSS), podcasts, Peer to Peer and other Social Book Marking Facilities (Veletsianos, 2010). Jenkin states that Web2.0 technologies enable immersive, participatory, socially involved and multi-modal experiences (Veletsianos, 2010). Such technologies can address the concerns raised by Distance Educationists such as Rose and Meyer, who rightly pointed out that the barriers to education are not always inherent in individuals but often have to do with learners' interaction with inflexible educational materials (Veletsianos, 2010). Further, Boyd states that Web 2.0 technology affords three affordances for Distance Education: Support for conversational interaction, support for social feedback and support for social interaction and feedback (Veletsianos, 2010).

One of the most important applications of the Web 2.0 technology is Social Networking. Face book is the most reputed and used Social Networking site. Though not a primary teaching based application, the Face book can be effectively used to supplement learning practices. In Distance Education, the primary issue affecting learners is that of isolation and alienation. Face Book can be used as an effective mechanism for transacting guided-didactic scheme of education. Similar is the case with applications like Twitter.

However, one of the most path breaking developments in the field of Web 2.0 is the integration of internet applications with mobile platforms.

A good number of educational institutions use mobile apps to impart high quality education. One of the cases in view is the KO-SU virtual class for mobile learners. It gives a number of features those are compatible with most smart phones with a provision for various value added services. It supports various exercises those can be added to the classes. The major drawback is that its free service supports only one class a month. Beyond this limit, a user fee is charged.

In a nutshell, the success in integrating state of the art ICT to the existing pedagogic structures depends on the following important aspects:

> Discovering the appropriate ICT tools those are easily accessible to both the teachers and learners. Such tools should be an obvious improvement of the existing state of technologies. Such technologies should also broaden the horizon of understanding related to the subject area.

$>$ Integration of ICT involves effective technology leadership. Effective technology leadership ensures that the technology is integrated at the correct point with 
limited fuss. The "how" and "when" factors are of paramount importance while dealing with integration of ICTs

$>$ To harness the full scope of ICT, the aspect of specializing appropriate technologies assumes importance. The maxim, "too many cooks spoil the broth" holds good. Today, a large number of complementary technologies exist in the market. Experimenting with all of them or many of them is often not a very good idea due to the time constraint as well as the technical complexities involved. A case in view is that of A-view and Wiz-IQ. Both are similar platforms, but using both of them for the same purpose is not often a very good idea. At the same time, there are instances that require integration of technologies of diverse hues, an aspect we shall dwell in some detail under the discussion on "convergence of technologies".

$>$ The use of technologies also hinge upon the question of the end use of these technologies. Higher cognitive applications need technologies those are different from those required for introductory applications. The role of an effective administrator is to find an effective solution to this vital issue in technopedagogy.

\section{GLOBALIZATION OF EDUCATION AND ISSUES RELATED TO EDUCATIONAL TECHNOLOGIES}

The process of infusion of Educational technology has been greatly aided by globalization in the educational field. GATS had a profound impact on the process of globalization of education.

The major provisions of GATS are presented in the paragraphs that follow. The traditional definition of Services terms it as an economic output that gets consumed as soon as it is produced, while there is a divergence in the time period between which a good is produced and consumed. For the same reason, trade in services requires a mix of cross-border transactions and local establishment rules (Wooton, 2000).

Again, consequent to this fact, GATS emphasizes both cross border barriers and barriers to local establishments without explicit preference to either, while the General Agreement on Trade and Tariffs (GATT) gives explicit preference to barriers at the borders like tariffs, Quota etc. GATS bring under its purview, any service in any sector, except those provided in exercise of Governmental Authority \{GATS-Article13 (B)\}.

However, the text goes on to say that any service provided on a commercial basis or in competition with one or more service providers will also is under its ambit. This provision has major implications for the education sector. The major modes of supply under GATS as applicable to Distance education are presented below:

\section{MODE1}

It covers the aspect of Cross- Border Trade; this covers all those activities in which a producer exports a service from its own territory to a consumer in a foreign country. For example, an educational Institution in India provides an on-line educational programme to students in another country.

\section{MODE2}

It pertains to consumption abroad. This takes care of all those cases where a consumer goes abroad to obtain a service. For example if a patient goes abroad for treatment or a student 
from one country visiting a foreign country to obtain a degree, it is a case of a service consumed abroad.

\section{MODE3}

It covers within its ambit the aspect of commercial presence. This implies that a service provider from one country sets up business subsidiary or branches in another country. For example, if IGNOU establishes its branches in foreign countries, it indicates the commercial presence of IGNOU in that country.

\section{MODE4}

It deals with the Movement of Natural Persons. In this case a member of the service-providing firm goes to the domestic territory of another country to provide a service there. Such movements are only for a short period of time. For Example, a Distance Learning institute of India sends its administrative officer to Dubai to manage the affairs of its branch there for a period of Five years. GATS enjoin upon its members certain obligations that can be grouped under two categories:

$>$ General Obligations and
$>$ Specific obligations

The General obligations are those that apply to all the service sectors irrespective of whether a country has made commitments on them or not. These can be noted as follows:

\section{Most Favored Nations Treatment (MFN)}

GATS stipulate the acceptance of Most Favoured Nations Status (MFN) in the case of services too. The MFN status stipulates that any commercial advantage provided to one of the signatories on a particular product must be provided to all other signatories who export a like product to the country.

For Example, if Government of India permits Alama Iqbal Open University (Pakistan) to run its programmes in India, the same facility must also be extended to Singapore National University if the latter requests the Government of India for the same.

\section{Obligations Related To Rule Framing and Implementation}

GATS enjoins its members to internationally notify/publish changes in laws, rules and regulations that have a bearing on international trade in services. Similarly, any regulation that the members frame to deal with business relations between service providers, especially those dealing with Foreign Service providers must be based on objective criteria and must be applied equally to all service providers ( "GATS Primer", 2001). Further, "Paragraph 4 of Article VI of the GATS calls upon the Council for Trade in Services to develop new disciplines to ensure that non-discriminatory measures relating to qualification requirements and procedures, technical standards and licensing requirements do not constitute unnecessary barriers to trade. As part of the implementation of this provision, the Services Council established the Working Party on Professional Services (WPPS) with the mandate to develop such disciplines in the area of professional services and designated the sector of accountancy as a priority" (ITD, 2004).

\section{Rules related to the working of Monopolies}

The GATS signatories should ensure that working of monopolies for providing services should not in any way violate the working of the country's MFN obligations (Friends of Earth, 2001). 
On the other hand Specific Obligations apply only to those service sectors in which a country has made commitments. They are

$>$ Market Access Obligations: As regards the market access obligations of member nations, GATS is very categorical in its approach. It states the following

$>$ "When a member undertakes a commitment it must indicate for each mode of supply what limitations, if any, it maintains on market access. Article XVI: 2 of the GATS list six categories of restrictions, which may not be adopted or maintained unless they are specified in the schedule. All scheduled limitations on market access therefore must fall into one of these categories. They comprise of four types of quantitative restrictions as well as limitations on foreign equity participation and on the types of legal entity permitted." (ITD, 2004)(www.itd.org/eol/e/wto06 27.htm\#note2)

$>$ National Treatment Obligation: GATS in its National Treatment obligation "under Article XVII requires members to accord to services and service suppliers of any member treatment no less favourable than that it accords to services and service suppliers of national origin" (ITD, 2004) (www.itd.org/eol/e/wto06 27.htm\#note2)

Notwithstanding anything that has been mentioned above, the GATS framework like GATT provides for certain explicit exceptions to GATS obligations. These exceptions have been provided under three heads: Temporary Exceptions, General Exceptions and Security Exceptions.

$>$ Temporary Exceptions to GATS provisions have been provided under Article XII, which provides for appropriate measures to safeguard precarious Balance of Payment positions (BOP) of nations.

$>$ General Exceptions to GATS provisions are provided under Article XIV to

- Protect public morals and to maintain public order. Public order is defined as "situations where a genuine and sufficiently serious threat is posed to one of the fundamental interests of society" (ITD, 2004) (www.itd.org/eol/e/wto06 25.htm\#note2)

- protect human, animal, plant life or health Security Exceptions to GATS obligations states "a member is allowed to take any action which it considers necessary for the protection of its essential security interests or in pursuance of its obligations under the United Nations Charter for the maintenance of international peace and security. Members are not required to furnish any information the disclosure of which would be contrary to their essential security interests" (ITD, 2004) (www.itd.org/eol/e/wto06 25.htm\#note2).

For purposes of classification of educational services, GATS accepts the following break-up of types of educational services based on UN's CPC classification. 
Table 1:

Education Services in the GATS Scheduling Guidelines and CPC

Sectoral Classification List
1. EDUCATIONAL SERVICES

A. Primary education services
Relevant CPC No.
B. Secondary education services
Definition/coverage in provisional CPC

Preschool education services: Pre-primary school education services. Such education services are usually provided by nursery schools, kindergartens, or special sections attached to primary schools, and aim primarily to introduce very young children to anticipated school-type environment. Exclusion: Child day-care services are classified in subclass $\mathbf{9 3 3 2 1 .}$ Other primary education services: Other primary school education services at the first level. Such education services are intended to give the students a basic education in diverse subjects, and are characterized by a relatively low specialization level. Exclusion: Services related to the provision of literacy programmes for adults are classified in subclass 92400 (Adult education services n.e.c.).

General secondary education services: General school education services at the second level, first stage. Such education services consist of education that continues the basic programmes taught at the primary education level, but usually on a more subject-oriented pattern and with some beginning specialization. Higher secondary education services: General school education services at the second level, second stage. Such education services consist of general education programmes covering a wide variety of subjects involving more specialization than at the first stage. The programmes intend to qualify students either for technical or vocational education or for university entrance without any special subject prerequisite. Technical and vocational secondary education services: Technical and vocational education services below the university level. Such education services consist of programmes emphasizing subject-matter specialization and instruction in both theoretical and practical skills. They usually apply to specific professions.

Technical and vocational secondary school-type education services for handicapped students: Technical and vocational secondary school-type 


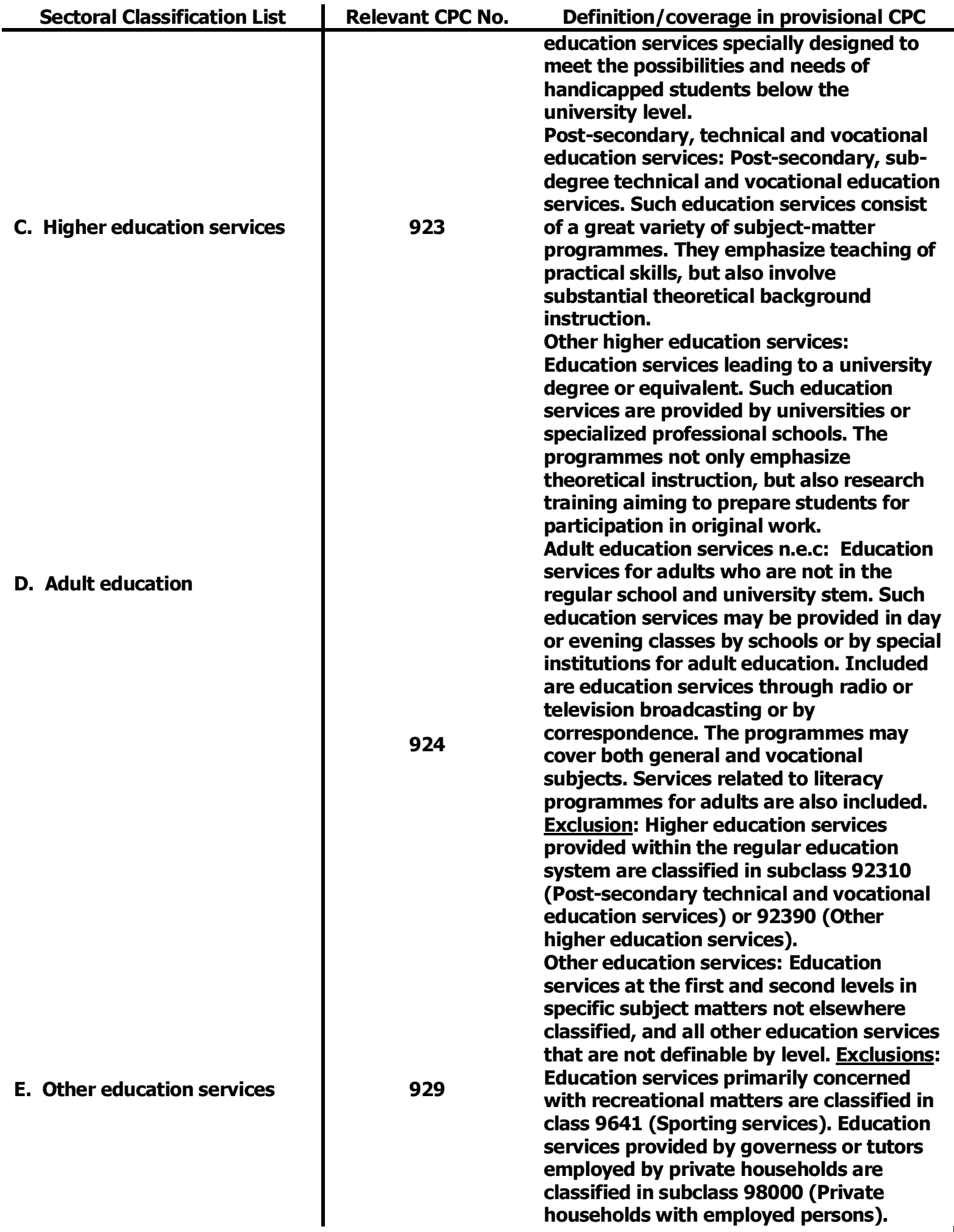

Source: United Nations, Provisional Central Product Classification, 1991. 
It is very clear from the foregoing discussion that GATS has a major bearing on the nature of liberalization of global education. However the maximum impact is to be seen in the field of Distance Education. Let us explore the issues related to technological implementation as far as liberalization in the field of education is concerned. Let us take the case of Cross Border Trade. This field is totally technology intensive. The latest example of Cross Border Trade linked Technologies is the MASSIVE OPEN ONLINE COURSEWARE (MOOC). MOOC is now touted as the low cost alternative to expensive higher education provided by traditional universities. MOOCs provide not only a wide range of choices to the student community but also give them the comfort of doing these courses at the conveniences of their homes or work place. Further, students have the benefit of a large number of reputed universities coming together to provide high quality education. One does not need to go beyond "COURSERA" to understand this. Indians are not avoiding these global phenomena. Of the 2.9 million registered users of MOOC, $2,50,000$ are from India. These numbers are sure to grow, given the fact that the relevant population in the age-group 15-34 is set to grow from 430 million in 2011 to 464 million in 2021. It seems for the time being that the future of Distance and Online Learning lies in MOOC.

\section{CONVERGENCE OF TECHNOLOGIES}

If we look at the CPC classification, it is clear that Distance Education falls under the category of Adult Education. The following passage needs to be noted:

"Included are education services through radio or television broadcasting or by correspondence. The programmes may cover both general and vocational subjects. Services related to literacy programmes for adults are also included".

The classification presumes the use of a wide range of technologies for imparting adult education. Such technologies are therefore an integral part of the process of liberalizing Adult Education.

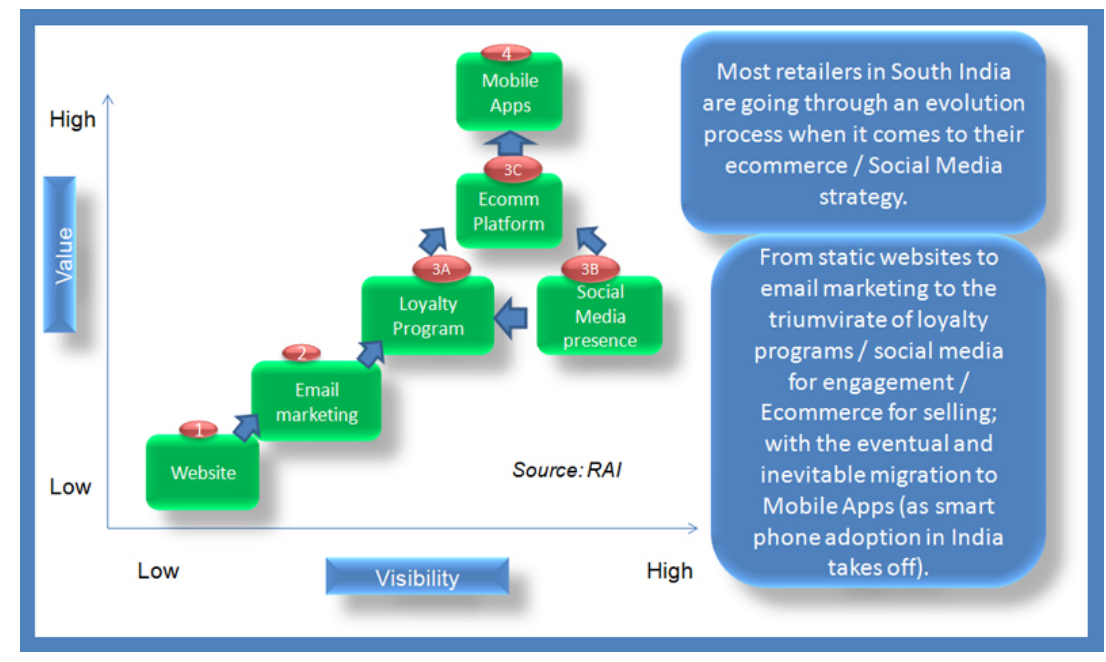

However, for technology infusion on a large scale in the field of education, a significant commercial ethos has to be infused. The flow chart presented below can be quite instructive: However, the biggest challenge emerges in the case of Die-Hard Traditionalists or Late Adaptors. Most of them are not only technology averse but also not keenly intent upon adopting 
or experimenting with technologies of any hue. Even among the "Teachers" we can easily find such persons.

As depicted in the chart of Retail Association of India (RAI), the days of reliance on a single technology is long over. In times of liberalization convergence of technologies is the key. Distance education can succeed only with the infusion of a large number of technologies.

However, the issue of convergence of technologies in Distance Education is a pretty vexed one. Let us understand the graph given below. Learners fall under various categories. Some of the learners, especially from the younger age groups adopt new technologies with far greater ease that those from higher age brackets. However, irrespective of their age, the ones accepting and adopting new technology at the earliest are the ones denoted as "Innovators" in the graph given below.

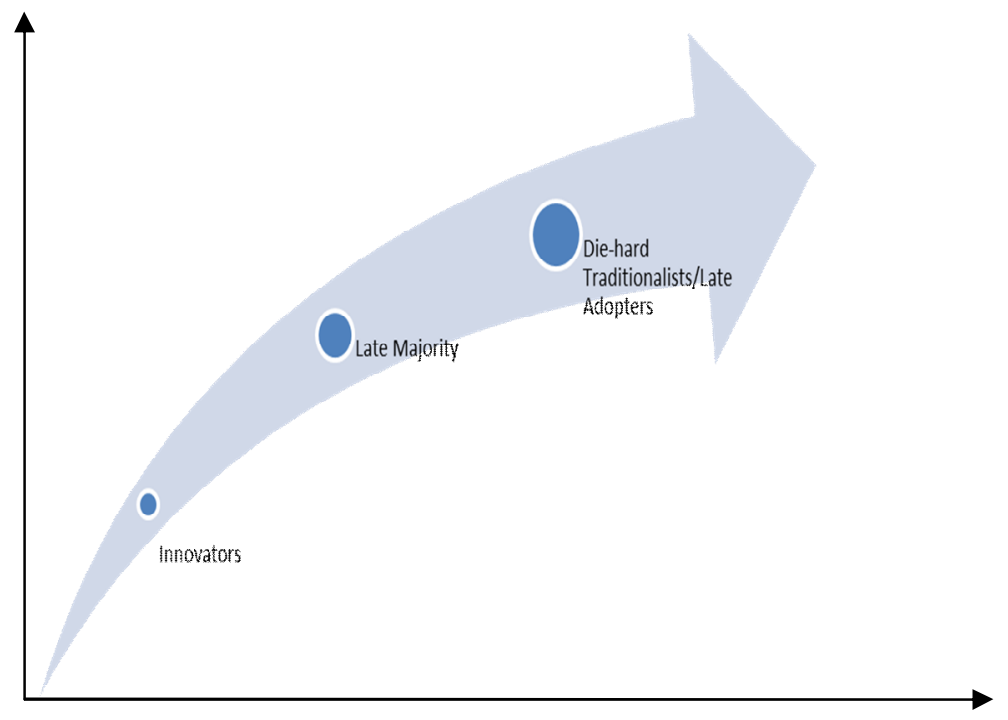

Time Required for Adopting New Technologies

Learners innovating with new technologies adopt technology based learning strategies at the earliest. For them, pure technology based learning strategies would be apt. A large numbers of complementary Learning Technologies can be implemented for their benefit on a single platform. Therefore convergence of technologies is most fruitfully obtained in such cases. The Second category is titled, "Late Majority".

Most learners fall under this category. A vast majority of the learners take time to identify the technologies most appropriate for them to be integrated into a single platform. Convergence of appropriate technologies is difficult but surely not impossible in this case.

However, the biggest challenge emerges in the case of Die-Hard Traditionalists or Late Adaptors. Most of them are not only technology averse but also not keenly intent upon adopting or experimenting with technologies of any hue. Even among the "Teachers" we can easily find such persons.

Convergence of technologies should take care of the following aspects (NCERT, March, 2006): 
$>$ recognition of the diversity of learners' needs, in the context of teaching and learning

$>$ recognition of not only the immediate needs but also the future needs

$>$ designing and implementing teaching- learning systems that could realize identified goals

$>$ Developing a range of support systems and training, creating the enabling systemic condition and materials, delivering them to the educational system, and training teachers and students to use them

$>$ Research into existing and new techniques, strategies and technologies for solving problems of education while enabling a judicious and appropriate application of technology.

$>$ Encourage Gamifying- that is using games like computer programmes for learning purposes (SVForum, 2011)

$>$ Broaden core subjects using technological inputs (SVForum, 2011)

$>$ Have measurable improvements for each student, especially un-performing students (Convergence of technology \& education: Using technology effectively in learning, 2011)

Past experience aimed at effecting convergence of technologies presents a mixed bag. It is seen very clearly that an equipment based approach seldom works. The experience of the SITE initiative shows that unless technology is adequately aided by effective intervention by teachers, equipped with programme notes or textual materials-the success of the intervention cannot be assured (NCERT, March, 2006).

Further, technologies should also enable the depiction of facets that could not be shown in a normal class room. It also needs to be noted that post programme research also has to support production teams, something that has not happened in India till date.

According to eminent pedagogy exert Scott P. Simkins, as far as technological innovations is concerned, it is not pedagogy itself that mattered, but how pedagogic innovation is used by taking into account the specific environment in which it is adopted (George, 2014). There was a need for individual faculty members to take these innovations and make them their own. He however emphasises the role of thoughtful innovation and discussion about how to make the best use of the new technologies on offer (George, 2014). In his experience, student interactive practices greatly improve learning in a variety of disciplines. In this scheme, he emphasises the role of Just in Time Teaching (JiTT) and Flipping the Class room methods (George, 2014). JiTT strategy is an internationally structured teaching and learning method that makes use of student responses to web-based questions that covered upcoming course materials.

The advantage of this mechanism is that it encouraged better preparation for course meetings and provided prompt feed back to students (George, 2014). Flipping the class room enables students to get maximum hands on experience and thereby it provided meaningful learning to them. Convergence of technologies is perhaps the most appropriate mechanism to achieve the objectives of JiTT and Flipping the Class room.

\section{SOCIO-CULTURAL FACTORS RELEVANT FOR THE CONVERGENCE OF TECHNOLOGIES}

The growth of any communication technology in a society and hence its applicability for Education depends to a very great extent on the degree to which policy makers recognize the importance of ICTs in promoting a knowledge based society. Many Developing Countries like 
India have realized the importance of giving a boost to New Information and Communication Technologies for the general betterment of the society. The Information Technology Act 2000 passed by the Indian Parliament is a step in the right direction. Many Countries have bestowed tax incentives on Communication technology based industries. Some Countries that have paid relatively scarce attention to the area of information technology are lagging behind in the field of spreading education using the latest technology. The failure of Distance Education in many African Countries can be attributed to this. Not only are policies important but also their implementation deserves greater attention. The road to failure is often paved with good intentions. Many structural factors make the implementation of technology a daunting task. At the planning stage the enormity of such factors are often not recognized.

The perceptions and attitudes of a political system greatly affect the acceptance and growth of technology in any society. The same holds true for all the ICTs relevant to Distance Education. A political system conscious of the payoffs of ICT for the enhancement of the educational profile of a country will frame appropriate policies for the adoption and dissemination of ICT throughout the length and breadth of the country. As A. W. Bates states while talking about his criteria of Media Selection, Novelty of an ICT should be the least important criteria that should guide the political society in deciding upon the ICT that should be selected. Rather than being guided by the fashion of the day, ICT should always be selected in accordance with its end result that is the extent to which it can bring about positive pedagogic out comes.

In Education, cost is an important factor that guides the adoption and growth of Communication Technology in a country. Developing Countries often lack the initial allocation as well as matching funds to make feasible investments in ICTs. Many countries often acquire costly technology without making provisions for building sufficient infrastructure to run them. Most Developing countries are constrained by resource scarcities. Even where the importance of ICTs is recognized, allocation for the development of these is at best paltry. Due to this, many developing countries are forced to depend on mostly traditional means of communication. These are limited in their efficiency. The Developing countries are vitally dependent on substantial foreign assistance to ensure the development of ICTs. Often it is found that it is very difficult to invite the attention of donors on ICTs. These countries are perennially short of Foreign Exchange for acquiring latest technologies. Most of the Developing Countries are undergoing Structural Adjustment Programmes under the auspices of the IMF.

Cost-efficiency of an ICT is another major factor that is important that determines its growth. Developing countries have to ensure that such a technology is adopted that is easily accessible to the target group and also fulfills all the functions that are expected of it. Such a scenario essentially implies that a costly technology need not always be the best technology. However, it is often seen that Developing Countries often invest in the latest technologies without considering whether the target audience is effectively reached or whether the target audience is interested in the technology.

Language is one of the major factors that hinder the easy assilimilation of ICTs by many developing countries. This hinders transfer of technology. The radio and TV programmes, computer software and the printed texts are produced in different countries bearing different cultural backgrounds. As such, such tools may fail to impress students of another country. For example, a zoology text can safely give the example of a koala in Australia, but the same cannot be replicated in India. With regard to cultural patterns there are two groups of policy makers. Policy makers can be Pro-implementation or Anti- implementation. It is precisely the 
cultural moorings of a society that makes people either in favor of implementing technology or to reject it.

Japanese have over the years built up a reputation of being quick to adapt and implement new technology. This can be linked to the way in which a new culture of receptivity to new ideas was built up after centuries of stagnation when commodore Perry forced the Japanese to open up their society.

Again, in recent times it has been seen that the culture of class room teaching and learning has been so strongly built into the psyche of the teaching community that they often exhibit resistance in the way of implementing technological change that forces a change in the role of the teacher from being a store house of all learning to a manager of the teaching-learning process. Very often, technology becomes the determining factor in the growth of ICT in any society. One would be justified in applying the Bates criteria for media selection as an appropriate parameter for selecting appropriate technology for educational purposes.

Bates states that the following are the major criterions that have to be taken into consideration while selecting appropriate media for Educational purposes

A - ACCESS TO THE MEDIA

C - COST OF THE PROPOSED MEDIA

T - TEACHING FUNCTIONS OF THE MEDIA IN RELATION TO LEARNING GOALS

I - INTERACTIVENESS AND USER-FRIENDLINESS

O - ORGANISATIONAL ISSUES

N - NOVELTY OF THE MEDIA

S - SPEED WITH WHICH CHANGE CAN BE BROUGHT ABOUT IN THE MEDIA (IGNOU, 2001).

With regard to the acceptance of a particular technology, the factors such as access, cost, teaching functions, instructiveness and user-friendliness, organizational issues and speed afforded to change are important issues.

In the case of Media selection, Bates regards Novelty of a media as the least important criterion on which a particular media should be selected or rejected. However, in the case of many third world countries, it is novelty of a media that attracts the attention of policy makers.

For example, in the late70s and $80 \mathrm{~s}$, the novelty of TV as a medium influenced the UGC to initiate the Country-Wide Class room programme for the benefit of the college students. However much care was not taken to ensure whether, the programme could generate enough interest in the student community to make the programme a success. Moreover, at the time of its initiation, access to TV sets was also a major problem. Even today the tele density in India stands at a low 80 per 1000. The end result was that UGC's CWC generated a utilization rate of less than $10 \%$.

Apart from the factors mentioned above, once a technology is selected, there are certain other factors that need the concern of policy makers. Handling of New technology needs care and technical proficiency. For this training is an important aspect. Many developing countries lack enough personnel to train manpower in new technology. Moreover, constant retraining of manpower to acquaint them with changing technology is also important. These often act as constraints before the smooth growth of ICT. 
Maintenance of equipment also needs sufficient care. Frequent snags may render equipments unusable. Maintenance as a function also needs sufficiently trained staff, high quality spare parts and machine friendly attitude from the users.

\section{A STUDY ON PERCEPTION OF TEACHERS ON CONVERGENCE OF TECHNOLOGIES}

In order to further understand the practical issues related to Convergence of technologies, a short questionnaire was administered by the researcher to teachers at various levels teaching across the state of Kerala.

The sample size of the study was 30 .

The demographic detail of the participants of the survey is given below:

\section{Gender-based Distribution}

The gender-wise distribution of the data of the study is given in the following table:

Table: 1

Gender based distribution

\begin{tabular}{|c|c|}
\hline $\begin{array}{c}\text { Number of Male } \\
\text { Respondents }\end{array}$ & $\begin{array}{c}\text { Number of Female } \\
\text { Respondents }\end{array}$ \\
\hline 14 & 16 \\
\hline
\end{tabular}

It is clear from the table given above that $54 \%$ of the respondents were females and the rest $46 \%$ of the respondents were males.

\section{Qualification-based Distribution}

The Qualification-based distribution of the data of the study is given in the following table:

Table: 2

Qualification Based distribution

\begin{tabular}{|c|c|c|}
\hline $\begin{array}{c}\text { Respondents } \\
\text { with a Doctoral } \\
\text { Qualification }\end{array}$ & $\begin{array}{c}\text { Respondents with a } \\
\text { Masters } \\
\text { Qualification }\end{array}$ & $\begin{array}{c}\text { Respondents with } \\
\text { a Bachelors } \\
\text { Qualification }\end{array}$ \\
\hline 03 & 19 & 08 \\
\hline
\end{tabular}

Of the respondents only $10 \%$ held a PhD qualification, while $64 \%$ of the respondents held a Masters Degree, while $\mathbf{2 6 \%}$ held only a Bachelors qualification. 
Table: 3

Type of Institution in which Employed

\begin{tabular}{|c|c|c|}
\hline Government & Semi Government & Private \\
\hline 20 & 04 & 06 \\
\hline
\end{tabular}

It is clear from the table that $67 \%$ of those who participated in the survey were teachers working in government institutions, while $13 \%$ represented Semi-Government institutions and the rest $\mathbf{2 0 \%}$ represented Private Education institutions.

\section{Experience in Years}

Table: 4

Experience in years

\begin{tabular}{|c|c|c|}
\hline $0-10$ & $10-20$ & $20-30$ \\
\hline 07 & 14 & 09 \\
\hline
\end{tabular}

The table under reference that the respondents were well experienced in the various institutions they were representing. $47 \%$ of the respondents had experience ranging between 10 and 20 years, while $30 \%$ had experience ranging from 20 to 30 years and the rest (23\%) had experience ranging upto 10 years.

Level up to which Taught

Table: 5

Level upto which taught

\begin{tabular}{|l|l|l|}
\hline Under Graduate & Post Graduate & No Response \\
\hline 16 & 4 & 10 \\
\hline
\end{tabular}

From the forgoing table it is clear that $53 \%$ of the respondents taught at the under-graduate level, $13 \%$ at the Post Graduate Level and $34 \%$ of the respondents did not indicate the levels at which they taught.

\section{Disciplines of the Teachers}

Table 6 : Disciplines of the teachers

\begin{tabular}{|l|l|l|l|}
\hline Management & Arts & Science & Education \\
\hline 02 & 13 & 02 & 13 \\
\hline
\end{tabular}

The discipline-wise distribution of teachers shows that $43 \%$ of the respondents were from the Arts faculty, $43 \%$ from the Education faculty, and $7 \%$ from Management and Science Faculty each. The issue specific response of the respondents is given the tables presented below: 


\section{Essentials of Technology Management}

The various parameters under this head were requested to be graded by the respondents on a scale of "1" to " 5 ", the former being the most important and the latter being the least important.

Table 7

Essentials of technology management

\begin{tabular}{|c|c|c|c|c|c|}
\hline Parameters & "1" & "2" & "3" & "4" & "5" \\
\hline Hands on skills in operating technologies and equipment & 14 & 5 & 6 & 3 & 2 \\
\hline Creativity and Ability to innovate & 14 & 5 & 6 & 2 & 2 \\
\hline $\begin{array}{l}\text { Experience in Technology Adaptation and Project } \\
\text { Management }\end{array}$ & 10 & 12 & 2 & 1 & 4 \\
\hline Adaptation to new technical and Creative Environment & 13 & 5 & 5 & 3 & 3 \\
\hline Team Spirit and Man Management Skills & 14 & 6 & 1 & 3 & 5 \\
\hline Good Language Skills esp. in English Language & 10 & 11 & 4 & 2 & 2 \\
\hline Government or Policy Support & 15 & 2 & 4 & 3 & 3 \\
\hline $\begin{array}{l}\text { Attitude of the Mgt towards technological assimilation \& } \\
\text { implementation }\end{array}$ & 13 & 7 & 3 & 4 & 3 \\
\hline
\end{tabular}

The respondents were asked to provide responses on issues those were closely related to Convergence of Technologies. The initial battery of questions was aimed at finding out the parameters, which in the opinion of the respondents contributed to efficient technology management. A large number of the respondents stated that hands on skills in operating technologies and equipment ranked highest in the scale of importance as an essential element of technology management $(47 \%)$, while a moderate number $(20 \%)$ felt it to be of medium importance. The pie chart given below is illustrative of this fact.

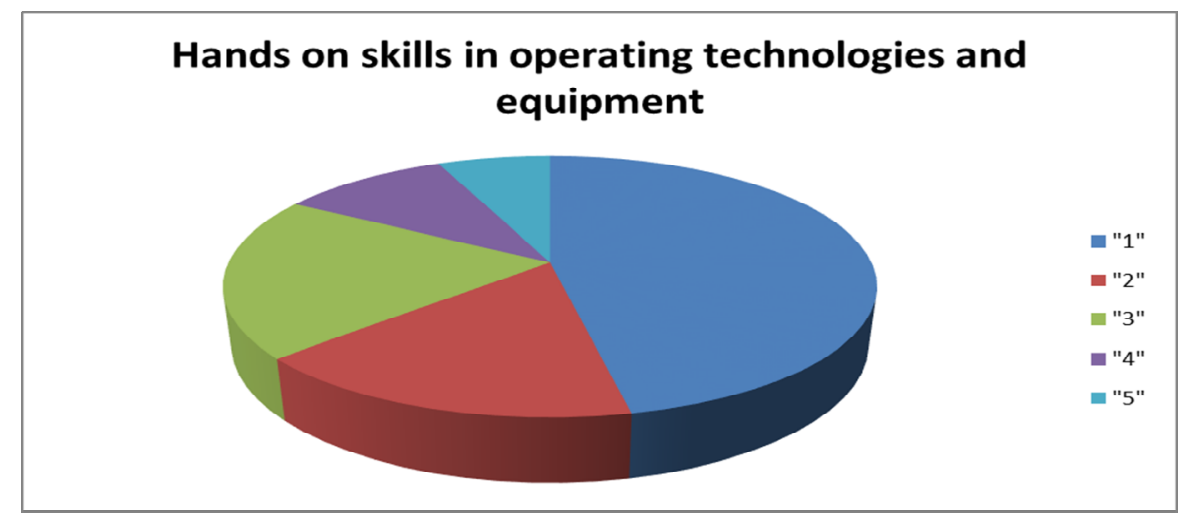

From the survey it is clear that Creativity and Ability to innovate is of primary importance in Technology Management (48\% of the respondents graded it in "scale 1 "). Only $6.7 \%$ of the respondents graded it as being of least importance, while a moderate number $(20 \%)$ felt it to be of medium importance 


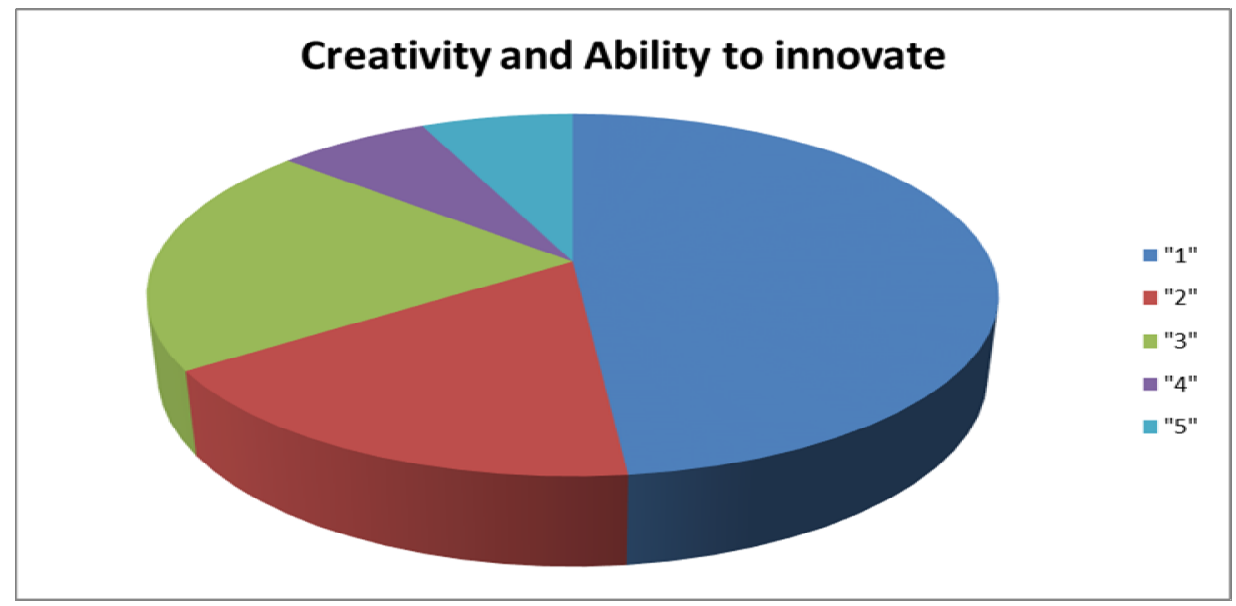

Experience in Technology Adaptation and Project Management is an important area of Technology Management as gleaned from the survey results. $75 \%$ of the respondents together opted for "1" and " 2 " on the scale provided.

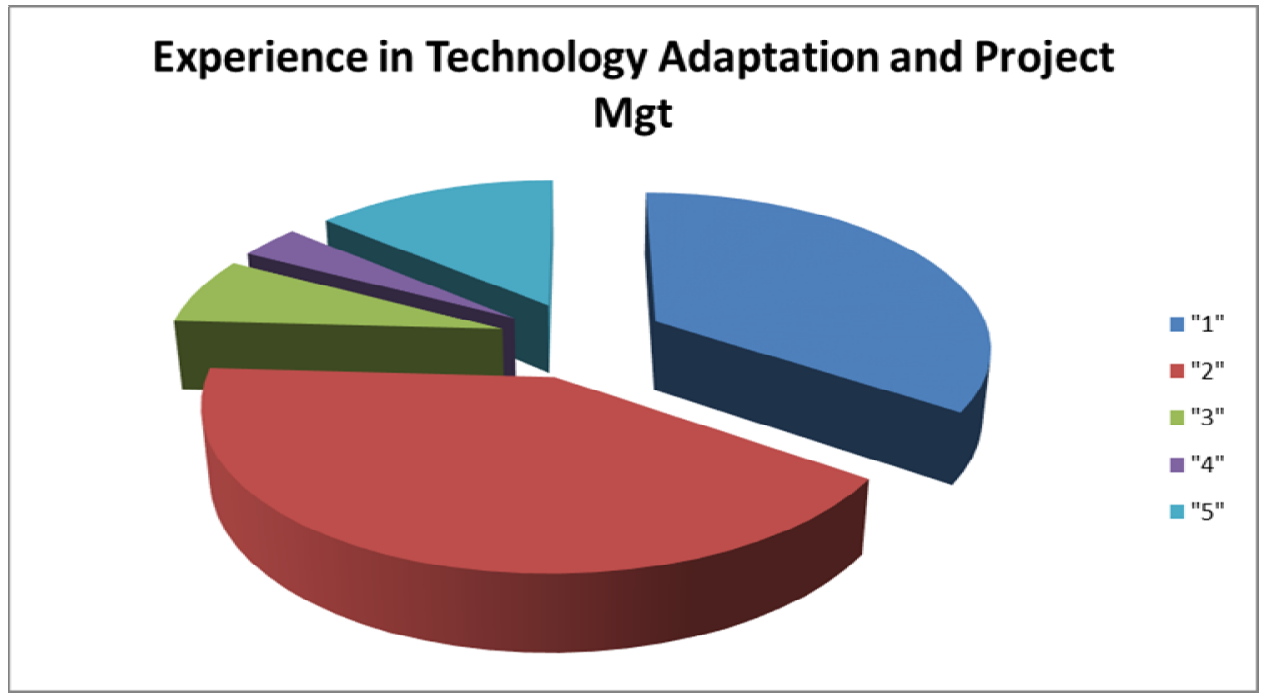

Qualitative research across the world has proved that Adaptation to new technical and Creative Environment is a basic factor in ensuring sound technology management. The current survey corroborates this view. As much as $45 \%$ of the respondents graded it on scale " 1 ". 


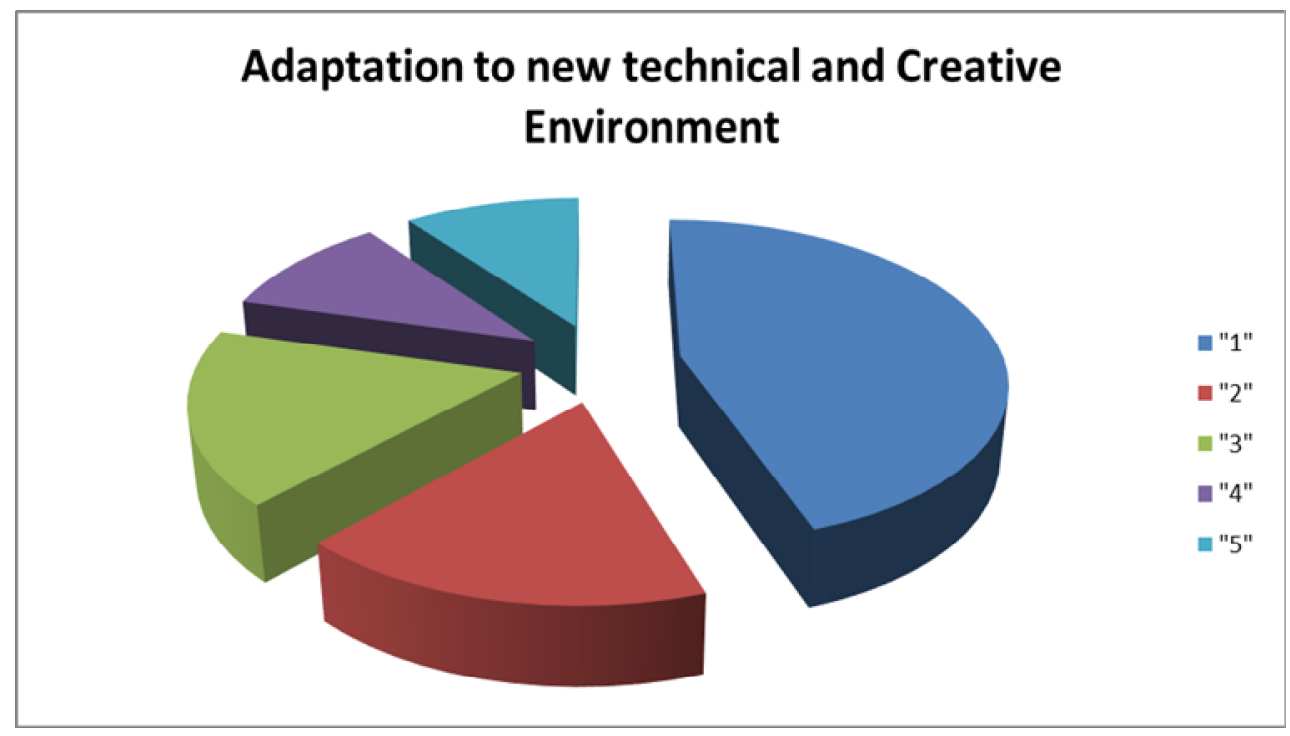

As is of common experience, working in a team is the sine-qua-non of every successful endeavor. To create a vibrant team, man management skills are of utmost importance. This attested by the results presented below, which shows that $48 \%$ of the respondents regard "Team Spirit and Man Management Skills" as of primary importance.

This should be seen in the light of the fact that $21 \%$ of the respondents also rated this parameter on the $2^{\text {nd }}$ scale of importance.

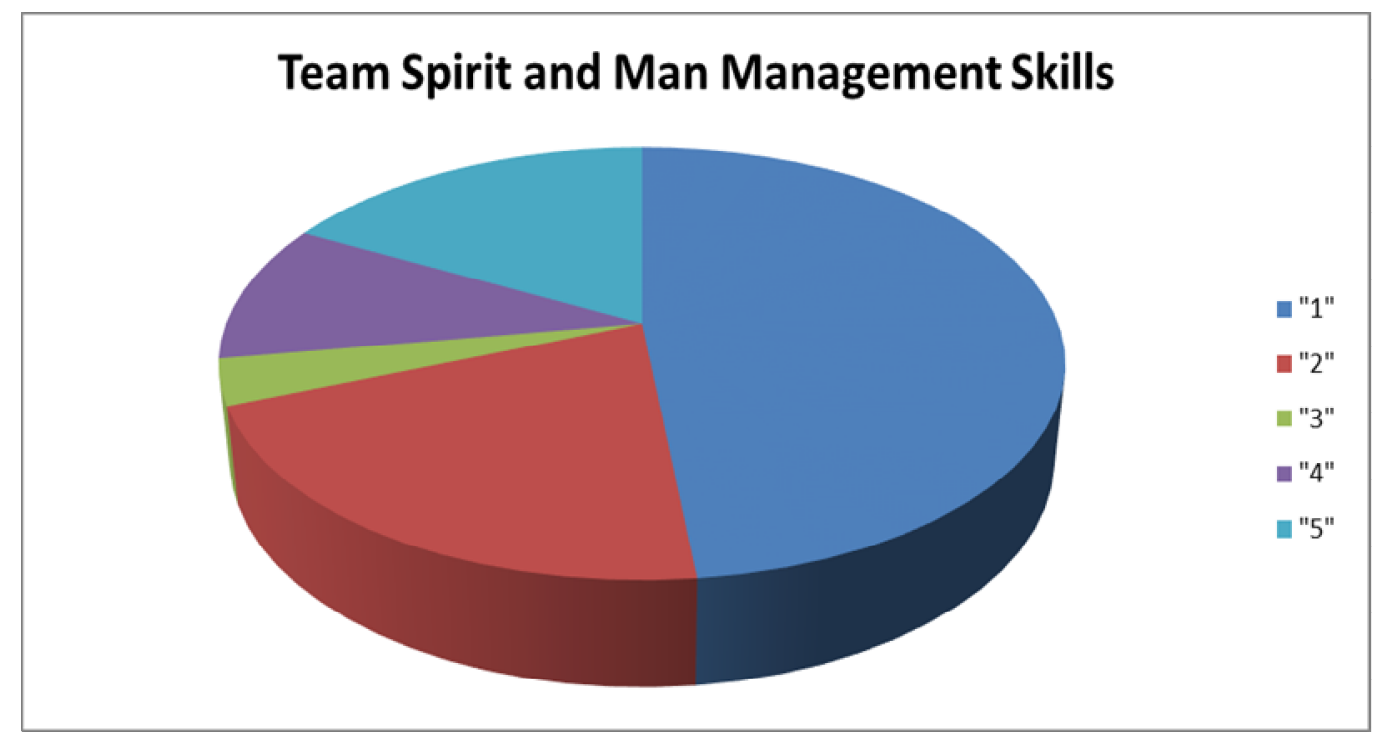

Most modern educational technology runs on platforms that utilize English language. $72 \%$ of the respondents feel that "Good Language skills especially in English Language" (combined score for scale" 1 " and " 2 ") is an essential factor in managing modern educational technology. 


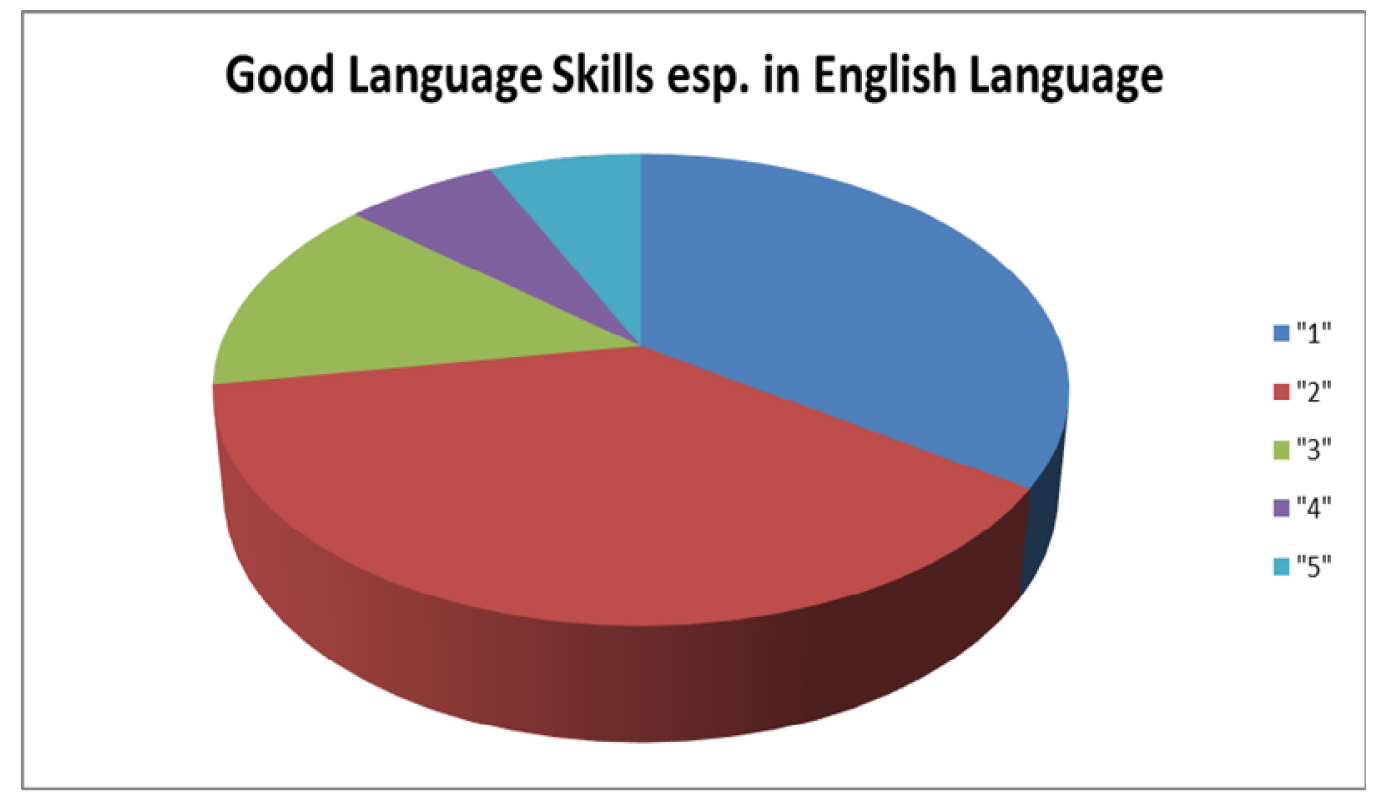

Governmental support has been revealed as an important aspect in the educational technology management. $56 \%$ of the respondents fell that this parameter is of primary importance. This could also be due to the reason that the flow of governmental financial support also critically hinges upon its policy framework.

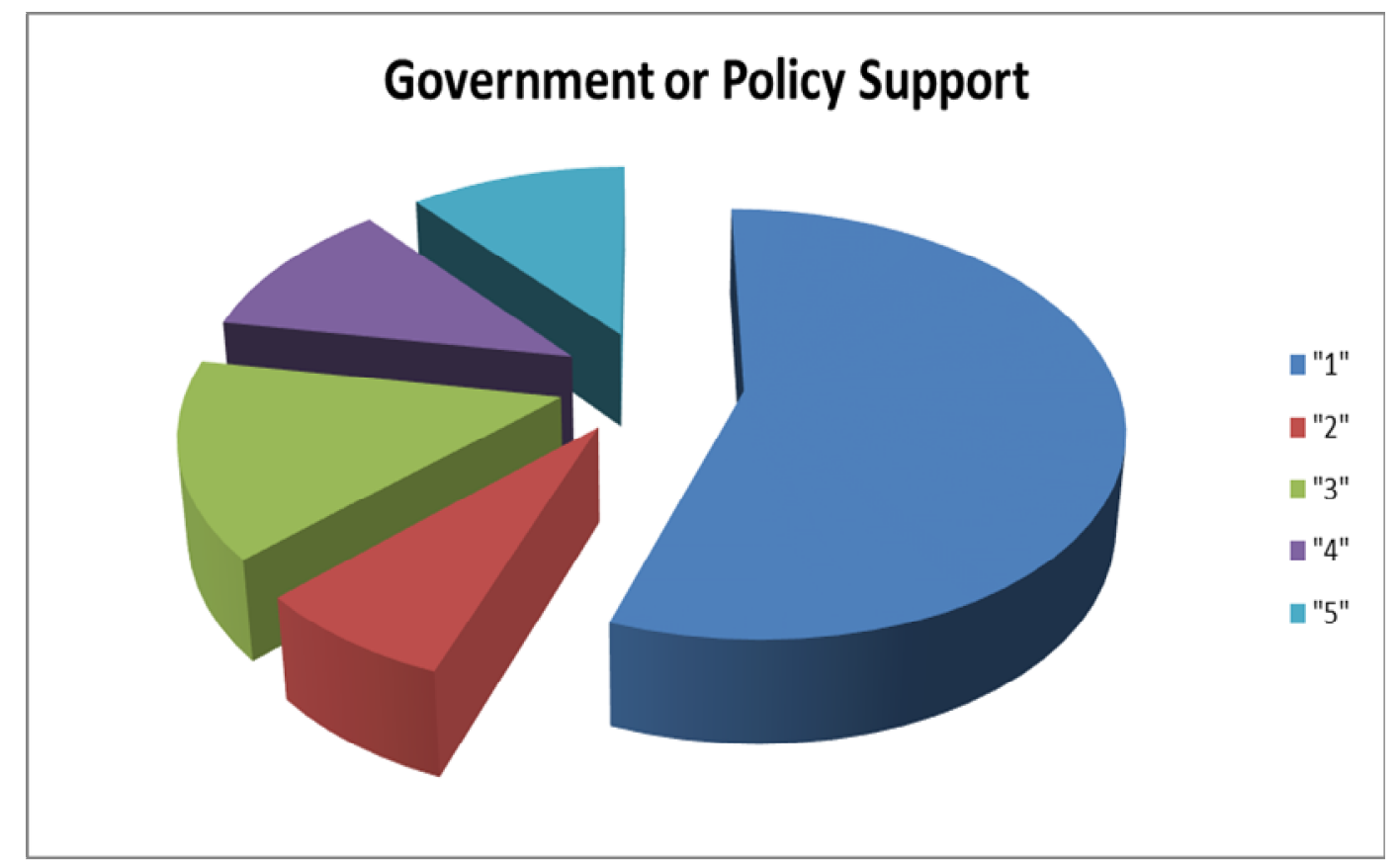

No matter, how attractive the technology is, the attitude of the host management is an essential factor in implementing and assimilating new educational technology. 
More than $66 \%$ of the participants in this survey feel the same way (scores on scale "1" \& scale "2").

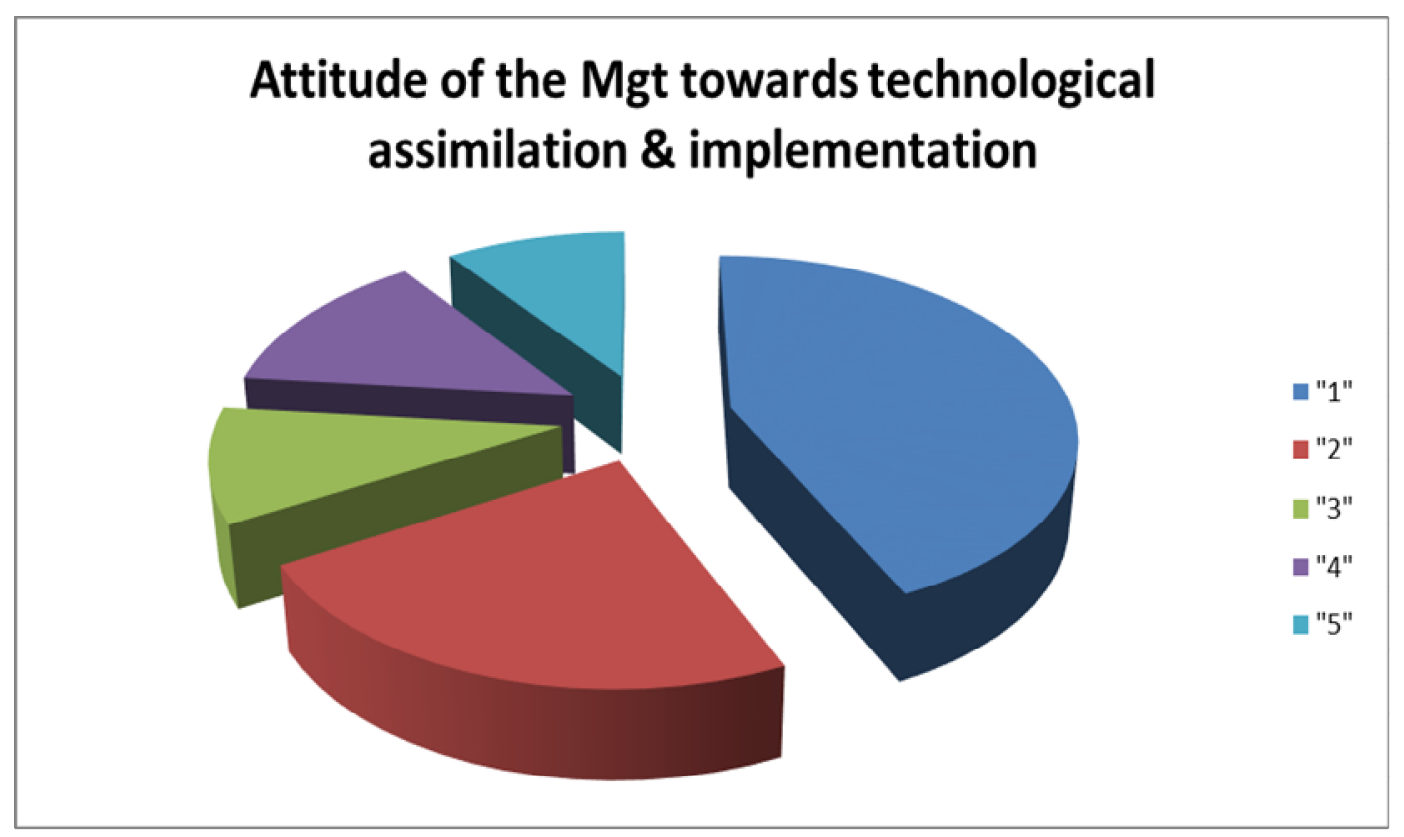

Individual Technologies Most Relevant for developing a Digital Learning Platform Among the large number of technologies that can be integrated into a digital learning platform, a shrewd decision maker has to select the most appropriate ones. This issue was put before the respondents who returned the results those can be viewed in the table that follows.

\begin{tabular}{|c|c|c|c|c|c|}
\hline Parameters & "1" & "2" & "3" & "4" & \\
\hline Land line Telephone & 14 & 5 & 3 & 2 & 3 \\
\hline Radio-Transmission & 9 & 10 & 5 & 1 & 3 \\
\hline Television & 14 & 5 & 3 & 1 & 5 \\
\hline Web-Conferencing & 16 & 7 & $\mathbf{0}$ & 2 & 3 \\
\hline On-Line Chat Board & 10 & 9 & 5 & 1 & 3 \\
\hline Group-Mailing & 8 & 7 & 5 & 5 & 3 \\
\hline Online Workbook & 11 & 5 & 9 & 0 & 3 \\
\hline Online Whiteboard & 15 & 7 & 3 & 1 & 2 \\
\hline PDA & 7 & 7 & 6 & 2 & 4 \\
\hline 2-D Model Projector & 8 & 7 & 6 & 3 & 3 \\
\hline 3-D Model Projector & 14 & 4 & 5 & 3 & 2 \\
\hline Video and Audio Player & 14 & 3 & 5 & 3 & 2 \\
\hline
\end{tabular}

The graph presented below shows intra group variation in choices of the respondents. 


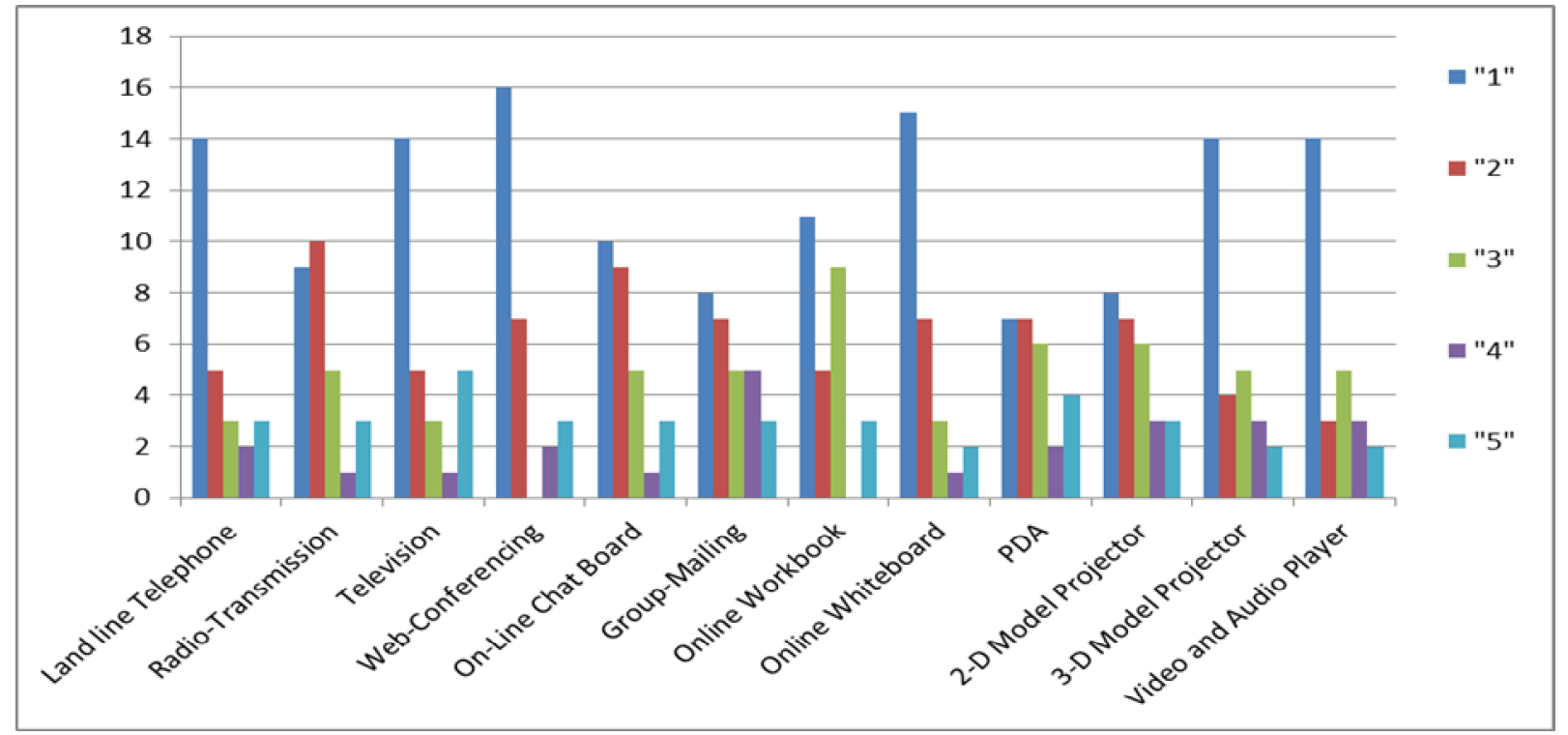

It is clear from the chart that scale " 1 " preference is the highest for the technologies- Land line telephone, TV, Web-Conferencing, On-line white boards, 3-D Model projectors and video and audio players. The line-diagram given below further elucidates the preferences.

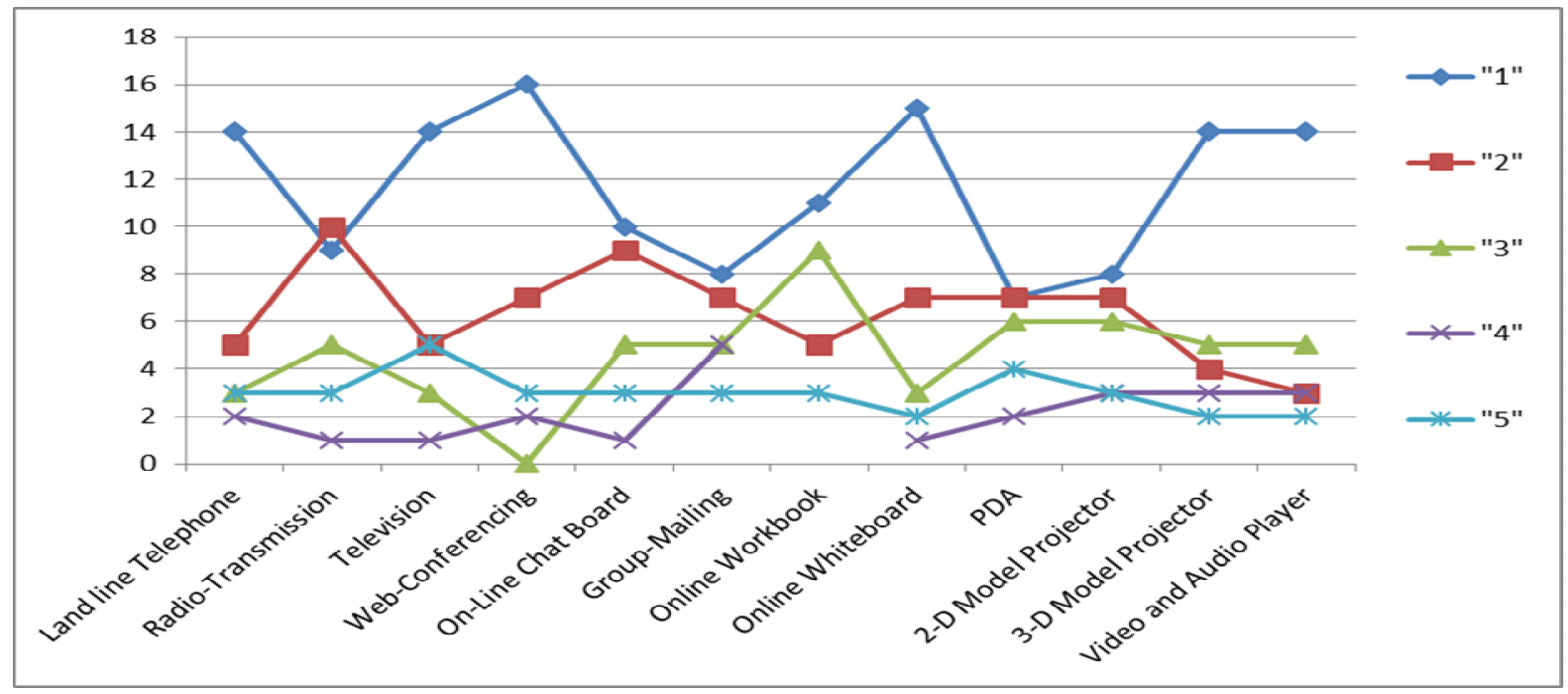

It is thus clear that technological convergence in the Indian context surely has to account for "Old Generation Technologies" on their platform as much as new technologies. While, WebConferencing, On-line white boards, 3-D Model projectors and video and audio players can be integrated into a synchronous or asynchronous digital platform, the importance of integrating older technologies such as Land line telephone and TV into such a platform has been emphasized by this study. 
Most Appropriate Combination of Technologies

Our respondents were requested to scale the most appropriate combination of educational technologies for convergence on a single platform. The table below gives the data obtained from the respondents.

\begin{tabular}{|c|c|c|c|c|c|}
\hline Parameters & "1" & "2" & "3" & "4" & \\
\hline Landline Telephone, Radio and TV & 15 & 7 & 7 & 0 & 1 \\
\hline $\begin{array}{l}\text { Web Conferencing, Online Workbook, Online Chat board, } \\
\text { Online White Board, PDA and 3D Model Projector }\end{array}$ & 11 & 12 & 1 & 2 & 3 \\
\hline $\begin{array}{l}\text { Web Conferencing, Online Workbook, Online Chat board, } \\
\text { Online White Board, PDA, 3D Model Projector and Group } \\
\text { mailing Facility }\end{array}$ & 17 & 9 & $\mathbf{0}$ & 1 & 2 \\
\hline
\end{tabular}

The results given in the table above are depicted in the line graph given below and are quite illustrative.

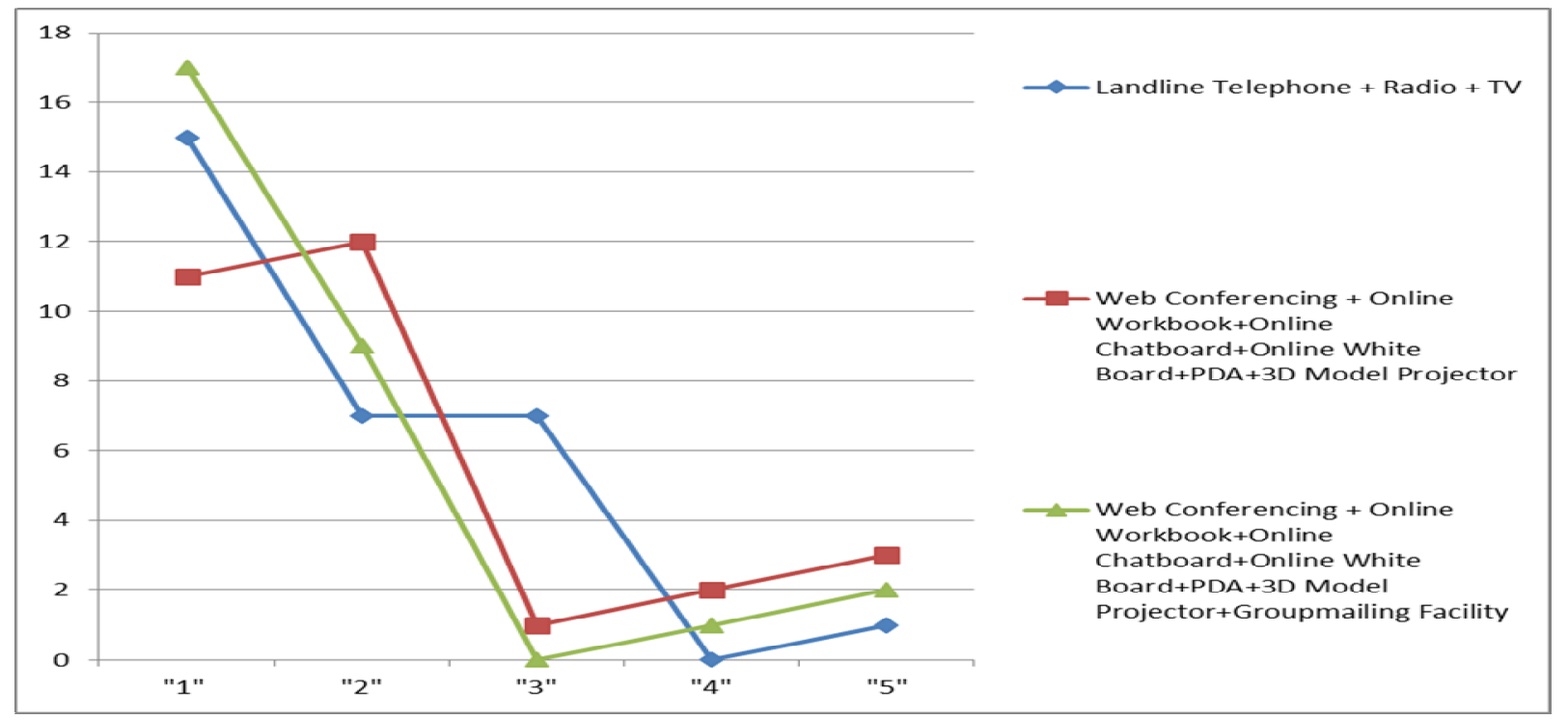

The preference of the teaching community for the technologies those need to be integrated into a technology based learning platform is very clear. Based on the Scale"1" and Scale "2" preference of the respondents, it is clear that they have expressed their opinion in favour of the combination, "Web Conferencing plus Online Workbook plus Online Chat board plus Online White Board plus PDA plus 3D Model Projector plus Group mailing Facility" for their vision of an ideal technology based educational platform.

\section{CONCLUSION}

In conclusion, one might be justified in stating that Convergence of technologies requires a high degree of planning for its success. While the technologies per se are an important factor, the social milieus in which these technologies are implemented are equally important.

The short study initiated by the author also makes it substantially clear that the teachers have a very clear perception on the convergence of technologies. Only when all relevant factors are 
taken into consideration, would there be an optimum technological platform that caters to diverse needs and would act as a solution to various constraints faced by the learner.

\section{BIODATA and CONTACT ADDRESS of the AUTHOR}

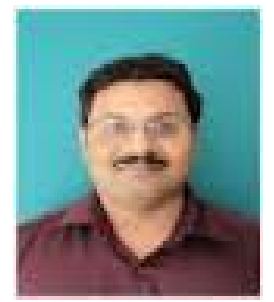

M. RAJESH is working as Regional Director at IGNOU Regional Centre, Cochin. He holds a Masters degree in International Relations and a doctorate on the topic, "Indian Distance Education in the era of GATS". He is an external PhD evaluator and guide in some of the reputed universities in India. He has been nominated to many committees within and outside IGNOU. He frequently delivers talks on various academic issues on electronic media.

M. RAJESH

Regional Director,

IGNOU Regional Centre, Cochin, INDIA

Phone: +91-9497721366

Email: rajesh cawes@yahoo.com]

\section{REFERENCES}

Friends of the Earth (2001) "GATS Primer". London, UK.

Amrita-Virtual-Interactive-E-Learning-world. (2013). Retrieved 10 24, 2013, from A-View: aview.in

Anderson, A. (2010). Learning to Learn in E-Learning-Constructive practices for Development. Orebro Studies in Informatics.

Convergence of technology \& education: Using technology effectively in learning. (2011, October 24). Retrieved from examiner.com: http://www.examiner.com/article/convergenceof-technology-education-using-technology-effectively-learning

Gaudelli, W. (2006). Convergence of Technology and Diversity:Experiences of Two Beginning Teachersin Web-Based Distance Learning for Global/Multicultural Education. Teacher Education Quarterly. Retrieved from http://files.eric.ed.gov/fulltext/EJ795200.pdf

George, S. B. (2014, January 20). Towards Innovative Pedagogy. The Hindu : Education Plus.

IGNOU. (2001). Media In Distance Education. Delhi: IGNOU.

IQ, W. (2013). Wiziq Education.online. Retrieved from wiziq: http://www1.wiziq.com/virtualclassroom/?gclid=CMSI8f7ss7oCFTF04godBUgAng

ITD. (2004). Retrieved from www.itd.org/eol/e/wto06_18.htm\#note1

Kirkwood, G. K. (2005). Information and Communication Technology (ICT) in higher education teaching- A tale of gradualism rather than revolution. Learning, Media and Technology (30(2)), 185-199. Retrieved 2013, from

http://www.tandfonline.com/doi/abs/10.1080/17439880500093810\#.UmDOBdJWZCQ 
MoodleTrust. (n.d.). Welcome to Moodle Community. Retrieved October 23rd, 2013, from Moodle: https://moodle.org

NCERT. (March, 2006). Position Paper of the National Focus Group on Educational Technology. New Delhi: Publication Division, NCERT.

SVForum. (2011, October 24). How to incorporate quality programs and technology into the education ecosystem? Retrieved from http://www.examiner.com/article/how-to-incorporatequality-programs-and-technology-into-the-education-ecosystem

Veletsianos, G. (2010). Emerging Technologies in Distance Education. Canada: Athabasca University.

Wooton, I. a. (2000). "Market Structure, Trade Liberalisation and GATS. Tinbergen Institute . 